\title{
Nocardia farcinica lung abscess presenting in the context of advanced HIV infection: Spontaneous resolution in response to highly active antiretroviral therapy alone
}

\author{
Arienne S King $\mathrm{PhD}^{1}$, Jose G Castro $\mathrm{MD}^{2}$, Gordon $\mathrm{CK}$ Dow $\mathrm{MD}^{1}$
}

\begin{abstract}
AS King, JG Castro, GCK Dow. Nocardia farcinica lung abscess presenting in the context of advanced HIV infection: Spontaneous resolution in response to highly active antiretroviral therapy alone. Can J Infect Dis Med Microbiol 2009;20(3):e103-e106.

A 43-year-old man, known to be HIV-positive, presented with a six-week history of symptoms including cough, hemoptysis, anterior chest pain, fever and wasting. His CD4 cell count was 46 cells/ $\mu \mathrm{L}$, and his chest $\mathrm{x}$-ray showed a cavitating lesion in the left upper lobe. Sputum culture was positive for Nocardia farcinica. His infection resolved following initiation of antiretroviral therapy. Nocardia is an uncommon opportunistic pathogen in patients with HIV infection and is usually associated with advanced CD4 depletion, cavitary pneumonia, metastatic infection and high mortality. The impact of antiretroviral therapy on Nocardia infection in the setting of HIV has not been clearly elucidated. The current report is the first to present a case in which a complete clinical cure of Nocardia pneumonia has been documented, primarily in response to highly active antiretroviral therapy alone.
\end{abstract}

Key Words: AIDS; Cavitary lung disease; Nocardia farcinica
Un abcès pulmonaire à Nocardia farcinica en présence d'une infection avancée par le VIH : Une résolution spontanée grâce à une simple antirétrovirothérapie hautement active

\begin{abstract}
Un homme de 43 ans qu'on savait séropositif au VIH a consulté en raison de symptômes de toux, d'hémoptysie, de douleurs thoraciques antérieures, de fièvre et de fonte musculaire. Sa numération de lymphocytes T CD4 était de 46 cellules/ $\mu \mathrm{L}$, et sa radiographie thoracique a révélé une lésion pulmonaire cavitaire du lobe supérieur gauche. Les cultures d'expectoration étaient positives au Nocardia farcinica. Son infection s'est résorbée après une antivirothérapie. Le Nocardia est un pathogène opportuniste peu courant chez les patients atteints d'une infection par le VIH et s'associe généralement à une déplétion avancée des lymphocytes T CD4, à une pneumonie cavitaire, à une infection métastatique et à un fort taux de mortalité. Les répercussions de l'antivirothérapie sur l'infection à Nocardia en présence d'un VIH ne sont pas clairement établies. Le présent rapport est le premier à présenter un cas qui documente la guérison clinique complète de la pneumonie à Nocardia, obtenue principalement grâce à une antirétrovirothérapie hautement active.
\end{abstract}

$N$ ocardia species are slow-growing, Gram-positive branching rods that are ubiquitous in soil. Thirteen species are recognized as opportunistic human pathogens. While Nocardia asteroides has been the most common species identified in human infection, there has been a relative increase in the isolation of Norcardia farcinica in recent series $(1,2)$. $N$ farcinica is characterized by opacification of Middlebrook agar and increased antimicrobial resistance to cephalosporins, cotrimoxazole and tetracyclines (3).

While impaired cell-mediated immunity is a significant risk factor for Nocardia infection, a substantial proportion of patients have no identifiable immunosuppression (4).

Despite the ubiquity of this organism in the environment, and its potential to infect apparently healthy hosts, Nocardia remains a rare cause of morbidity and mortality in persons infected with HIV in North America and Europe.

\section{CASE PRESENTATION}

A 43-year-old man diagnosed with HIV infection in 2000, and heretofore refusing all antiretroviral therapy, presented in May 2006 with a weight loss of $18 \mathrm{~kg}$ over six months, a three-month history of fatigue and weakness, and a six-week history of lower respiratory tract symptoms including cough, chest pain, bright red hemoptysis and shortness of breath on exertion. The respiratory symptoms were accompanied by progressive weakness and anorexia. He initially presented to the emergency department of his local hospital and received a 10-day course of oral levofloxacin. His chest x-ray showed a vague interstitial-alveolar infiltrate in the left upper lobe. He reported some improvement and returned to work after seven days; his condition subsequently deteriorated. His fatigue increased, and his cough and hemoptysis persisted. He was prescribed a course of clarithromycin from his family doctor, with minimal improvement, and subsequently presented again to the emergency department of his local hospital, where he was admitted.

His chest $\mathrm{x}$-ray on admission showed consolidation in the apical segment of the left upper lobe (Figure 1). Computed tomography scan revealed multiple thick-walled cavities (Figure 2). Two sputum samples obtained before transfer were smear-negative for acid-fast bacilli. His Mantoux skin test showed no induration, and he had no history of exposure to

${ }^{1}$ Department of Internal Medicine, The Moncton Hospital, Moncton, New Brunswick; ${ }^{2}$ Department of Medicine, Division of Infectious Diseases, Miller School of Medicine, University of Miami, Miami, Florida, USA

Correspondence: Dr Gordon CK Dow, Department of Internal Medicine, The Moncton Hospital, 135 MacBeath Avenue, Moncton,

New Brunswick E1C 628. Telephone 506-857-5670

Received for publication September 18, 2007. Accepted October 30, 2008 


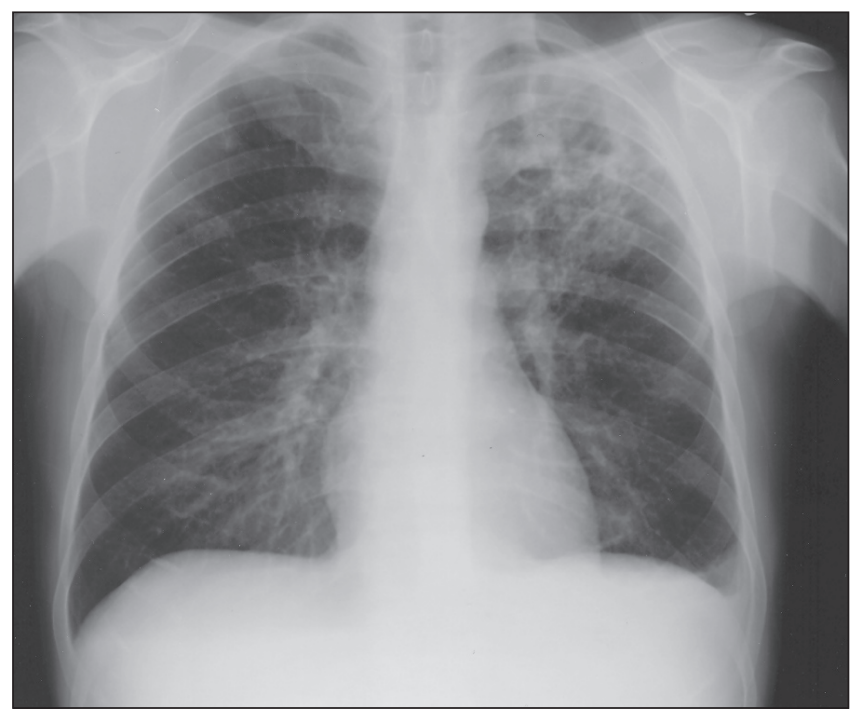

Figure 1) Chest $x$-ray on admission to hospital. Note the infiltrate in the left upper lobe

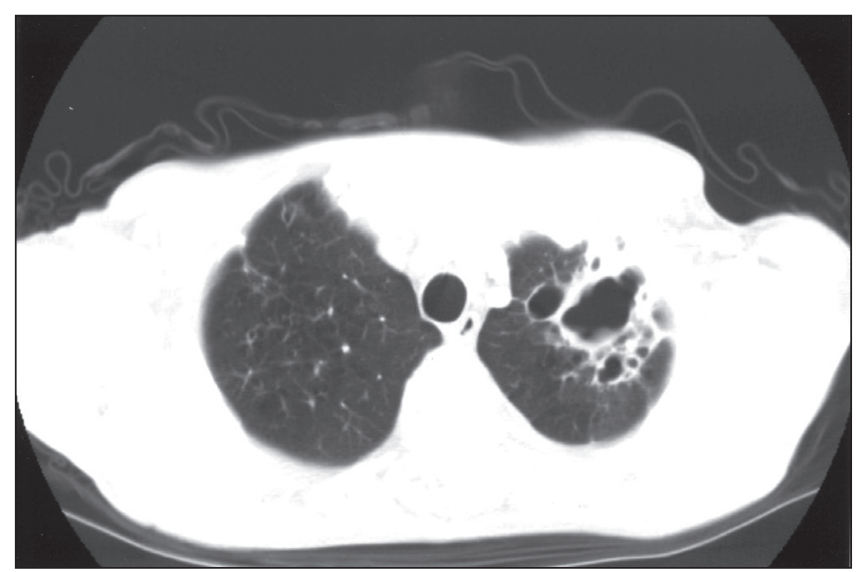

Figure 2) Computed tomography scan of chest at admission showing multiple thick-walled cavities within left upper lobe pneumonic infiltrate

tuberculosis. Cytological stain for Pneumocystis species in sputum was negative. Initial sputum cultures showed a heavy growth of Pseudomonas aeruginosa. The patient was treated with intravenous ciprofloxacin and cloxacillin for six days. He showed minimal improvement on this therapy and was transferred to the infectious disease service of The Moncton Hospital (Moncton, New Brunswick) in mid-June, 2006.

On arrival, the patient was cachectic and pale. His temperature was $37.7^{\circ} \mathrm{C}$, his resting pulse was 107 beats $/ \mathrm{min}$, his respiratory rate was 18 breaths/min and his blood pressure was $119 / 80 \mathrm{mmHg}$. He had oral thrush and axillary lymphadenopathy. He had extensive psoriatic plaques; otherwise, his physical examination was unremarkable. His breath sounds were normal, there were no murmurs and the abdomen was soft and nontender without organomegaly.

Laboratory testing revealed normal electrolyte, blood urea nitrogen, creatinine and random glucose levels. The patient's albumin level was grossly depressed at $21 \mathrm{~g} / \mathrm{L}$; serum folate concentration was low. Liver enzyme levels, including lactate dehydrogenase, were normal. Routine blood work showed a white blood cell count of $9.9 \times 10^{9} / \mathrm{L}$,

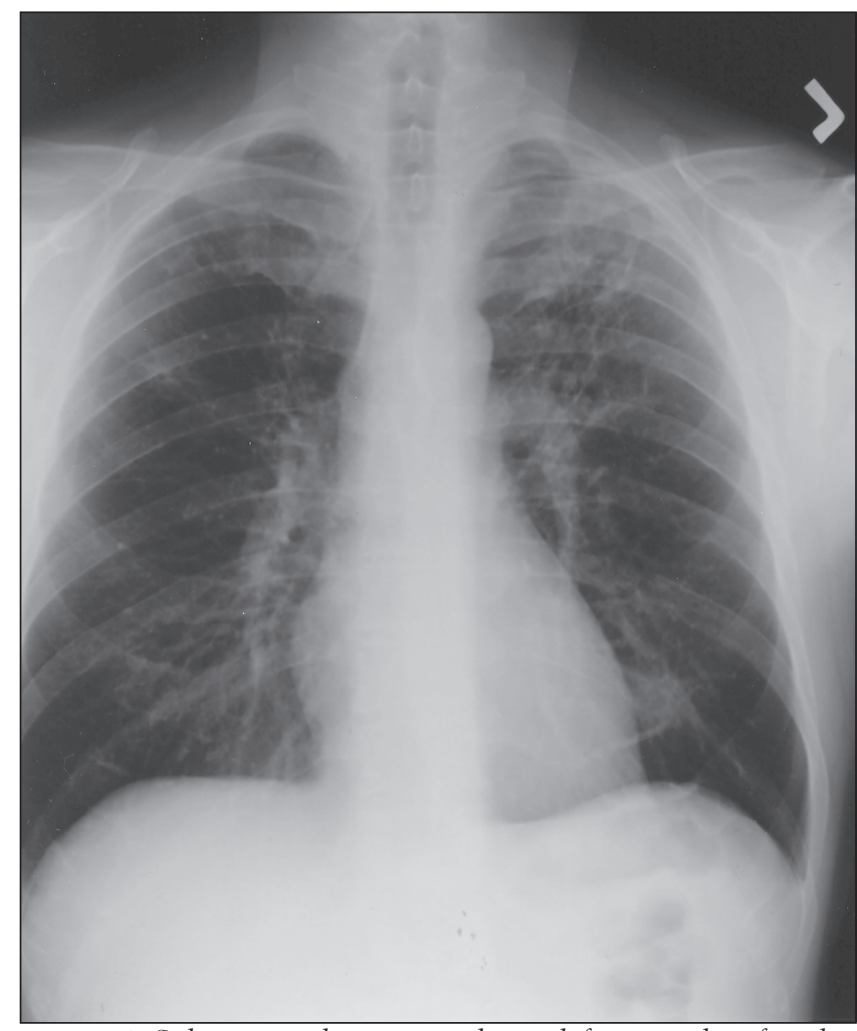

Figure 3) Subsequent chest $x$-ray obtained five months after discharge from hospital. Note the resolution of the cavitating lesion in the left upper lobe

hemoglobin level of $114 \mathrm{~g} / \mathrm{L}$ and a platelet count of $249 \times 10^{9} /$ L. Lymphopenia was marked with a profound depression of the CD4 cell count (46 cells/ $\mu \mathrm{L}$; CD4 7\%). The viral load was 117,000 copies $/ \mathrm{mL}$.

The patient's sputum cultures obtained after transfer revealed fluoroquinolone-resistant $P$ aeruginosa; ciprofloxacin and cloxacillin were replaced with intravenous piperacillin/tazobactam (given for 28 days) and gentamicin (given for 12 days). Antiretroviral therapy was initiated $24 \mathrm{~h}$ after transfer, with atazanavir boosted with ritonavir and combined with abacavir and lamivudine. Prophylaxis against Pneumocystis jiroveci pneumonia was initiated with double-strength cotrimoxazole given once daily. On this regimen, the patient began to improve, although the etiology of his cavitary pneumonia had not yet been established. Mycobacterial cultures of sputum, urine and blood were all negative. A later report from a sputum culture obtained at his referring hospital revealed acid-fast rods suggestive of Rhodococcus species, and the patient was started on rifabutin and azithromycin. Subsequently, the organisms previously reported as Rhodococcus were identified as $N$ farcinica. The isolate was sensitive to amikacin, amoxicillin-clavulanate, ceftriaxone, imipenem, minocycline and cotrimoxazole. The isolate demonstrated intermediate sensitivity to ciprofloxacin and clarithromycin, and it was resistant to tobramycin. There was a five-month span before receipt of the updated report. Rifabutin and azithromycin were then discontinued, and by that time, his pneumonia had resolved clinically and radiologically (Figure 3).

At the five-month follow-up appointment, his CD4 cell count had risen to $140 \times 10^{9}$ cells $/ \mu \mathrm{L}$, and the viral load was 
undetectable (less than 400 copies/mL). His psoriatic eruption had resolved completely.

Two years postadmission, he remains well and his CD4 cell count is 202 cells/ $\mu \mathrm{L}$.

\section{DISCUSSION}

Nocardia was first reported as a complication of chronic HIV infection in 1985 (4). Since that time, approximately 300 cases of opportunistic nocardiosis in the setting of HIV infection have been described worldwide. We were able to identify 161 cases published in peer-reviewed journals before the era of highly active antiretroviral therapy (HAART), 115 cases in the post-HAART era and 60 cases at the intersection of these two eras.

The prevalence of Nocardia in persons with AIDS in North America was $0.3 \%$ during the early 1980 s (4). A Spanish series (5) described a similar prevalence $(0.38 \%)$ in persons with AIDS between 1981 and 2000 .

This likely represents an underestimate due to challenges in microbiological identification and under-reporting of Nocardia infection. Nocardia isolation in respiratory secretions is hampered by its slow growth. Without selective media, it will usually be obscured by other more rapidly growing flora. It is also destroyed by the methods traditionally used to decontaminate sputum before mycobacteriological culture (3).

The prevalence of Nocardia infection is known to undergo seasonal and geographical variation (6). Miami has the highest reported prevalence of Nocardia and AIDS (1.8\%) in North America - 30 cases were identified at Jackson Memorial Hospital (USA) between 1985 and 1989 (7). A recent study (8) from the same centre between 1999 and 2004 identified 19 more cases, with a prevalence of $0.1 \%$ in persons with AIDS. This provides further support for the observation that Nocardia, similar to other opportunistic infections in AIDS, is declining in the developed world since the introduction of HAART.

Nocardia complicating AIDS appears to be most common in the developing world, where it has a prevalence of approximately $4 \%(3,9)$.

The predominant route of inoculation by Nocardia is by inhalation, or less commonly by direct infection of soft tissue through traumatic injury. Reflecting these modes of acquisition, Nocardia usually presents in patients with HIV as a chronic pneumonia syndrome ( $75 \%$ to $90 \%$ ) or soft tissue infection $(5 \%$ to $15 \%)(3,7,10-12)$. The presentation of Nocardia in HIVinfected patients is similar to patients without HIV, but it is more likely to be associated with extrapulmonary dissemination $(7,8,13)$. If defined as an established infection occurring at a noncutaneous extrapulmonary site, disseminated disease was seen in $84 \%$ of persons in the pre-HAART era, but appears to be less prevalent in more recent series (13). Common sites of extrapulmonary spread include central nervous system, bone and joint, liver and pericardium.

Presenting symptoms are nonspecific and usually consist of cough and shortness of breath for several weeks duration, usually associated with fever and progressive weight loss. Cutaneous abscess formation or pericarditis appears to be more common in HIV patients with active injection drug use, suggesting that direct inoculation may be a significant risk factor in this population $(6,7)$.
The radiographic appearance of pulmonary nocardiosis is nonspecific, and most commonly presents with upper lobe consolidation or reticulonodular infiltrates (14). Progression toward cavitation is more common in patients with HIV infection, and is seen in $60 \%$ to $80 \%$ of patients (7).

Nocardia infection in the HIV population tends to be associated with advanced immunodeficiency. The CD4 cell count is less than 200 cells $/ \mu \mathrm{L}$ in the vast majority of patients and less than 50 cells $/ \mu \mathrm{L}$ in $50 \%$ to $85 \%(8,11)$. Nocardia appears to be more common in patients not receiving active treatment for their HIV, and in one recent series (8), 37\% of patients with Nocardia infection presented with previously undiagnosed HIV infection. Intravenous drug use also appears to be a risk factor for nocardiosis in the developed world $(6,7)$.

Nocardia infection in patients with HIV is often complicated by other coinfections such as Mycobacterium tuberculosis (15), Mycobacterium avium complex (16-18), P aeruginosa (19) and $P$ jiroveci $(20,21)$.

First-line therapy for all strains of Nocardia infection has traditionally been sulfonamides; however, cotrimoxazole therapy has been found to be more effective than sulfonamide monotherapy (22). This complicates treatment in the HIVpositive population, in which the prevalence of hypersensitivity or intolerance to cotrimoxazole ranges from $20 \%$ to $50 \%$. $(13,23)$. A dose of $15 \mathrm{mg} / \mathrm{kg} /$ day (trimethoprim component) is suggested for the immunocompromised host, often in combination with a second active antimicrobial agent. Second-line agents against Nocardia species include ceftriaxone, minocycline, imipenem and amikacin; sensitivity is seen in greater than $70 \%$ of isolates of $N$ asteroides, Nocardia nova and Nocardia brasiliensis (22). $N$ farcinica is typically more drug-resistant, but usually retains sensitivity to amikacin, ciprofloxacin and imipenem. $(3,22,24)$. An alternative to cotrimoxazole must be utilized in the setting of sulfa resistance (common with $\mathrm{N}$ otitidiscaviarum), sulfa intolerance and for those patients failing sulfonamide therapy. The combination of imipenem and amikacin has demonstrated good activity clinically, as well as in animal models and in vitro (12,25). Parenteral therapy can generally be stepped down to oral therapy after three to six weeks, once a clinical response has been achieved (25). The best-studied oral alternatives to cotrimoxazole are minocycline and amoxicillin-clavulanate $(3,26)$. Long-term oral therapy should be guided by susceptibility data.

Debate remains in the literature about an appropriate length of treatment for nocardiosis in the setting of HIV infection. While 12 weeks of therapy appears to be adequate for minor cutaneous infections, most authors recommend at least one year of therapy for a primary course of treatment for patients with pulmonary or disseminated disease $(6,11,13)$. Relapse is common in patients not receiving antiretroviral therapy. Uttamchandani et al (7) found that 22 of 27 AIDS patients showed clinical improvement on antinocardial therapy; however, $64 \%$ of patients had relapsing infections once antibiotics were stopped. Relapse was associated with shorter treatment duration and a mortality of approximately $80 \%$. This has prompted the recommendation that low-dose maintenance therapy should be considered indefinitely (13). Our case suggests that this may not be necessary in the HAART era; there is currently no literature indicating at what point maintenance therapy can be safely discontinued. 
Nocardia is associated with a high mortality in the HIVpositive population. Poor outcome is associated with disseminated infection, delayed diagnosis and early discontinuation of treatment (7). A retrospective study (27) of the English-language literature in the pre-HARRT era highlighted a $74 \%$ mortality. This seems high in light of current, improved antiretroviral therapies. A more recent review (28) cited a 33\% mortality in Nocardia-infected HIV-positive patients.

Our patient did not receive first-line antimicrobial therapy due to a delay in laboratory reporting. His dose of cotrimoxazole, while suitable for $P$ jiroveci prophylaxis, would have been subtherapeutic for $N$ farcinica infection. While cotrimoxazole prophylaxis probably does reduce the incidence of nocardiosis in AIDS, there have been numerous reports of Nocardia infection developing while on prophylaxis with this agent $(3,11,22,26)$. His response could have been due, in part, to the 28-day parenteral course of antibiotics he received for $P$ aeruginosa. Susceptibility testing showed sensitivity to beta-lactam agents. His isolate of $N$ farcinica showed only intermediate susceptibility to the macrolide clarithromycin. Thus, his oral course of azithromycin and rifabutin would have been of limited benefit. Rapid institution of antiretroviral therapy and subsequent immune reconstitution probably played a pivotal role in his rapid recovery, particularly in light of the grim prognosis of this infection seen in the

\section{REFERENCES}

1. Schaal KP, Lee HJ. Actinomycete infections in humans - a review. Gene 1992;115:201-11.

2. Boiron P, Provost F, Chevrier G, Dupont B. Review of nocardial infections in France 1987 to 1990. Eur J Clin Microbiol Infect Dis 1992;11:709-14.

3. Jones N, Khoosal M, Louw M, Karstaedt A. Nocardia infection as a complication of HIV in South Africa. J Infect 2000;41:232-9.

4. Holtz HA, Lavery DP, Kapila R. Actinomycetales infection in the acquired immunodeficiency syndrome. Ann Int Med 1985;102:203-5.

5. Pintado V, Gómez-Mampaso E, Cobo J, et al. Nocardial infection in patients infected with the human immunodeficiency virus. Clin Microbiol Infect 2003;9:716-20.

6. Márquez-Diaz F, Soto-Ramirez LE, Sifuentes-Osornio J. Nocardiasis in patients with HIV infection. AIDS Patient Care STDs 1998;12:825-32.

7. Uttamchandani RB, Daikos GL, Reyes R, et al. Nocardiosis in 30 patients with advanced human immunodeficiency virus infection: Clinical features and outcome. Clin Infect Dis 1994;18:348-53.

8. Castro JG, Espinoza L. Nocardia species infections in a large county hospital in Miami: 6 years experience. J Infect 2007;54:358-61.

9. Lucas SB, Hounnou A, Peacock C, et al. The mortality and pathology of HIV infection in a West African city. AIDS 1993; 7:1675-6.

10. Kageyama A, Yazawa K, Ishikawa J, Hotta K, Nishimura K, Mikami Y. Nocardial infections in Japan from 1992 to 2001, including the first report of infection by Nocardia transvalensis. Eur J Epidemiol 2004;19:383-9.

11. Walensky RP, Moore RD. A case series of 59 patients with nocardiosis. Infect Dis Clin Prac 2001;10:249-54.

12. Farina C, Boiron P, Goglio A, Provost F. Human nocardiosis in northern Italy from 1982 to 1992 . Scand J Infect Dis 1995;27:23-7.

13. Javaly K, Horowitz HW, Wormser GP. Nocardiosis in patients with human immunodeficiency virus infection. Medicine (Baltimore) 1992;71:128-38.

14. Kramer MR, Uttamchandani RB. The radiographic appearance of pulmonary nocardiosis associated with AIDS. Chest 1990;98:382-5.

15. Lynn W, Whyte M, Weber J. Nocardia, mycobacteria and AIDS. AIDS 1989;3:766-7.
pre-HAART era. There are no other reports in the literature of such a dramatic clinical resolution of Nocardia pneumonia with antiretroviral therapy.

Although it is a recognized opportunistic pathogen, infection with Nocardia species is not considered to be an AIDS-defining illness due to its rarity, and the fact that a substantial proportion of Nocardia infections are not associated with any known underlying immune deficit (4). Our patient was diagnosed with AIDS based on AIDS-wasting syndrome.

The surprising rarity of Nocardia infection in patients with AIDS is likely to be multifactorial. Nocardia is probably underdiagnosed due to its nonspecific clinical and radiological presentation, the frequency of other coinfections and difficult laboratory isolation. Because it is a soil saprophyte, the degree of environmental exposure is probably a significant determinant of its relative incidence. Finally, the frequent use of cotrimoxazole prophylaxis and effective antiretroviral therapies in Europe and North America will potentially contribute to its ongoing rarity in those populations infected with HIV. For these same reasons, its relatively high incidence in some parts of Sub-Saharan Africa may continue. Nocardia infection is frequently overlooked as a potential pathogen and should always be part of the differential diagnosis in HIV patients with advanced CD4 depletion and cavitary pneumonia.

16. Trinidad JM, Teira R, Zubero S, Santamaría JM. Coinfección por Nocardia asteroides y Mycobacterium avium-intracellulare en paciente con sida. Enf Infec y Microbiol Clin 1992;10:70-1.

17. Benadouia F, Libbrecht E, Boiron P, Fur A, Croix JC. Pneumonie extensive à Nocardia asteroides chez un patient sidéen. Méd Mal Infect 2001;31:447-8.

18. Luketombunga J-C, Virally J, Jagot J-L, Elhadad A, Lebarbier C, Mathieu M. Nocardiose pulmonaire et fistule bronchooesophagienne chez un patient infecté par le VIH. Rev Mal Respir 2004;21:147-51.

19. Marín Casanova P, García Martos P, Fernández Gutiérrez del Álamo C, García Herruzo J, Escribano Moriana JC, Aznar Martín A. Nocardiosis en paciented con SIDA. Rev Clin Esp 1991;188:83-4.

20. Soubani AO, Ibrahim I. Simultaneous nocardial empyema and Pneumocystis carinii pneumonia as an initial manifestation of HIV infection. South Med J 1993;86:1318-9.

21. Rodriguez JL, Barrio JL, Pitchenik AE. Pulmonary nocardiosis in the acquired immunodeficiency syndrome: Diagnosis with bronchoalveolar lavage and treatment with non-sulphur containing drugs. Chest 1986;90:912-4.

22. Lederman ER, Crum NF. A case series and focused review of nocardiosis: Clinical and microbiologic aspects. Medicine (Baltimore) 2004;83:300-13.

23. Gordin FM, Simon GL, Wofsy CB, Mills J. Adverse reactions to trimethoprim-sulfamethoxazole in patients with the acquired immunodeficiency syndrome. Ann Int Med 1984;10:495-9.

24. Miralles GD. Disseminated Nocardia farcinica infection in an AIDS patient. Eur J Clin Microbiol Infect Dis 1994;13:497-500.

25. Nocardia infections. Am J Transplant 2004; 4(Suppl 10):47-50.

26. Kim J, Minamoto GY, Grieco MH. Nocardial infection as a complication of AIDS: Report of six cases and review. Rev Infect Dis 1991;13:624-9.

27. Long PF. A retrospective study of Nocardia infections associated with the acquired immune deficiency syndrome. Infection 1994;22:362-3.

28. Martínez Tomás R, Menéndez Villaneuva R, Reyes Calzada S, et al. Pulmonary nocardiosis: Risk factors and outcomes. Respirology 2007;12:394-400. 


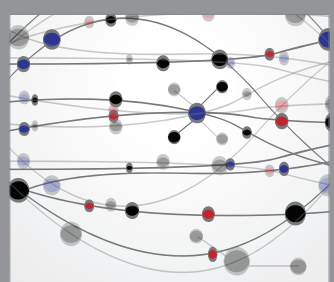

The Scientific World Journal
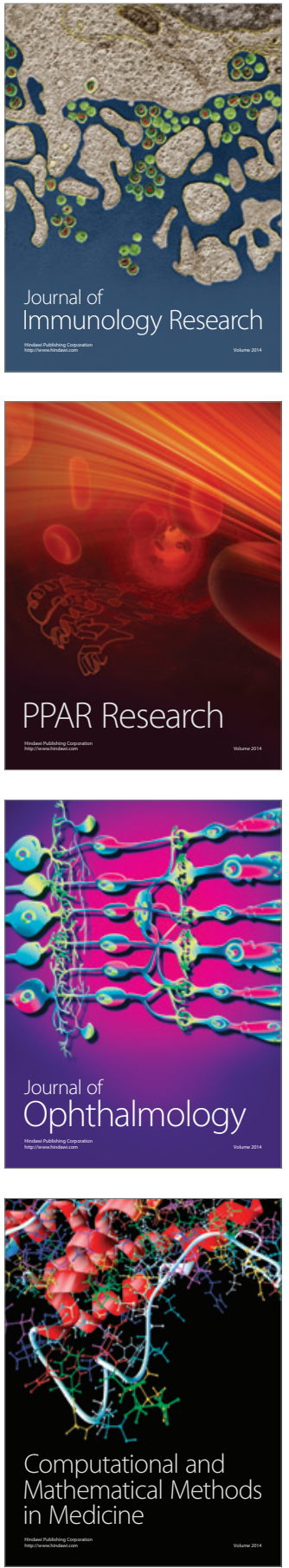

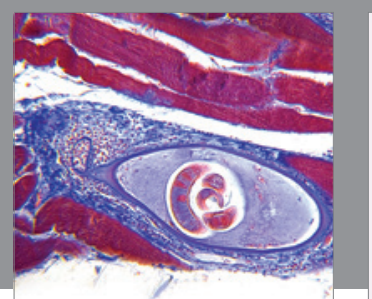

Gastroenterology Research and Practice

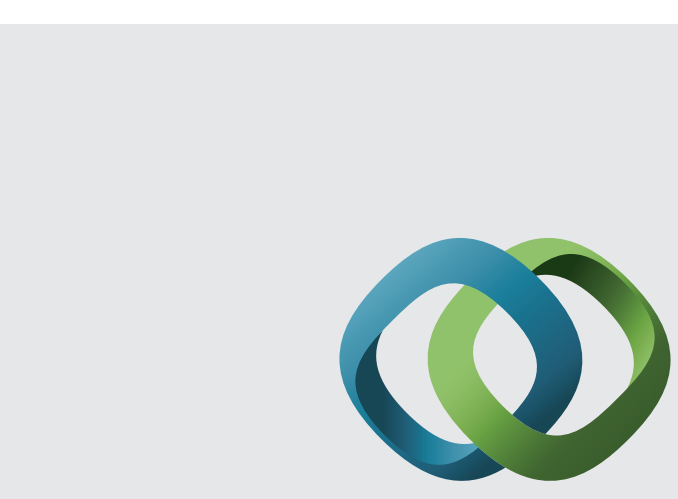

\section{Hindawi}

Submit your manuscripts at

http://www.hindawi.com
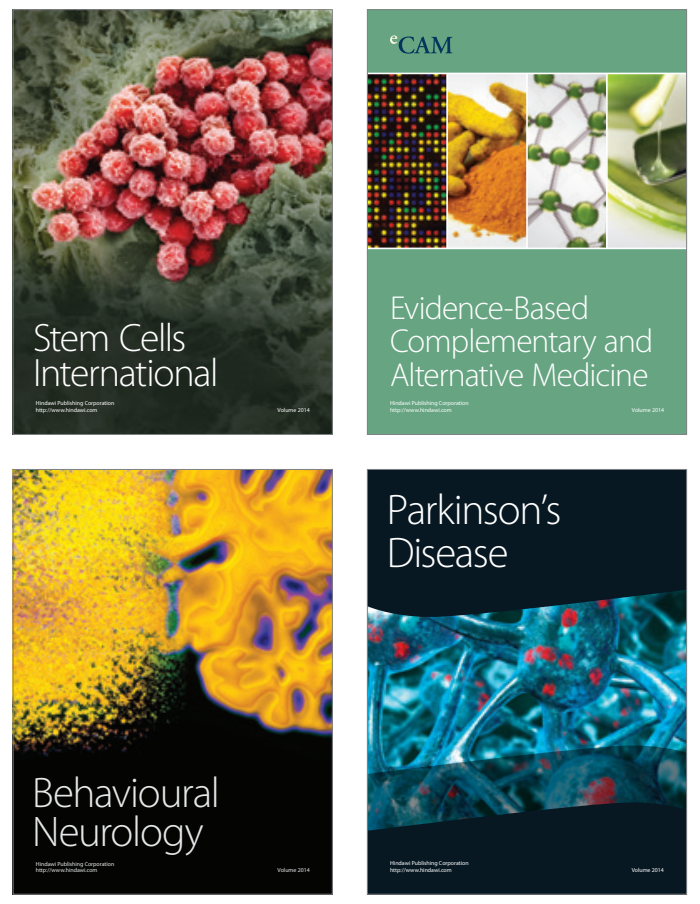
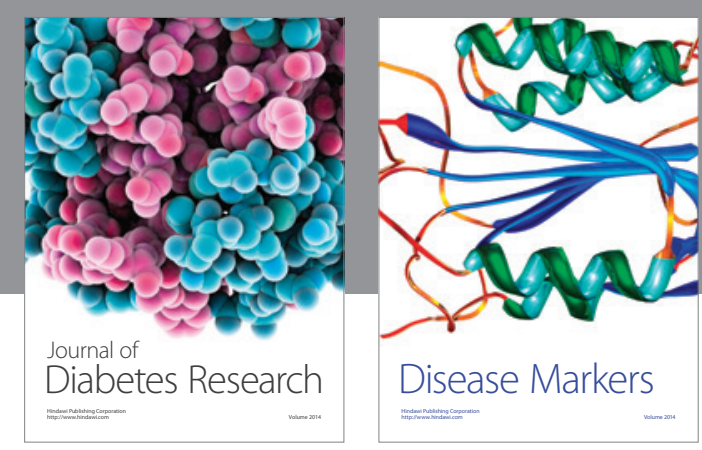

Disease Markers
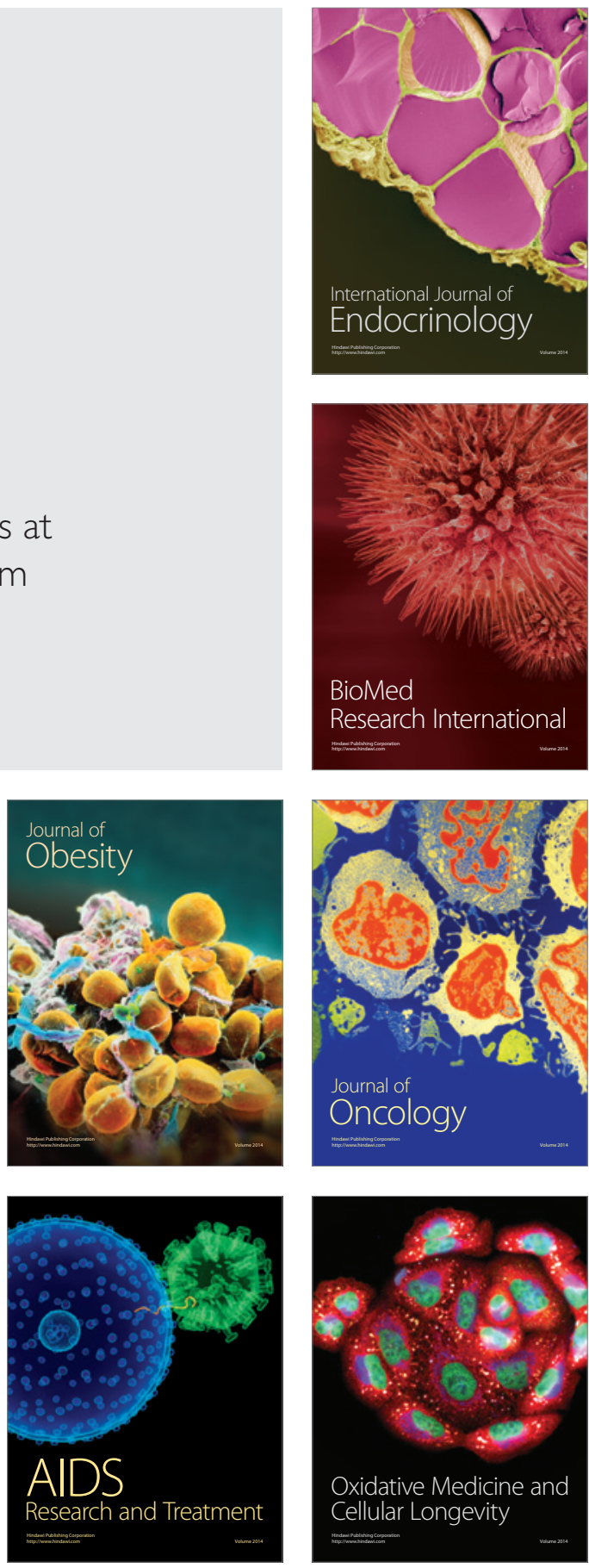